Kingdom Atomic Energy Authority mortality study. $\mathrm{Br} \mathcal{F}$ Ind Med 1987;44:149-60.

12 Wilkinson GS, Tietjen GL, Wiggs LD, et al. Mortality among plutonium and other radiation workers at a plutonium weapons facility. $A m \mathcal{F}$ Epidemiol 1987;125:231-50.

13 Checkoway H, Pearce N, Crawford-Brown DJ, Cragle DL. Radiation doses and cause-specific mortality among workers at a nuclear materials fabrication plant. Am ₹ Epidemiol 1988;127:255-66.

14 Rinsky RA, Melius JM, Hornung RW, et al. Case-control study of lung cancer in civilian employees at the Portsmouth naval shipyard, Kittery, Maine. Am F Epidemiol 1988;127:55-64.

15 Office of Population Censuses and Surveys. Classification of occupations 1970. London: HMSO, 1970.

16 World Health Organisation. International classification of diseases, injuries and causes of death. 8th Revision, 1965. Geneva: WHO, 1967.

17 World Health Organisation. International classification of diseases, injuries and causes of death. 9th Revision, 1975. Geneva: WHO, 1977.

18 Smith JW, Inskip H. Estimation of below measurement threshold doses following the remeasurement of a sample of old films. Fournal of the Society for Radiological Protection 1985;5:159-64.

19 Bailar JC, Ederer F. Significance factors for the ratio of a Poisson variable to its expectation. Biometrics 1964;20:639-43.

20 Breslow NE, Day NE. Statistical methods in cancer research. Vol II. The design and analysis of cohort studies. Lyons: International Agency for Research on Cancer, 1987. (IARC scientific publications, No 82.)

21 Office of Population Censuses and Surveys. Occupational mortality, 1970-72. Decennial supplement. London: HMSO, 1978. (Series DS, No 1.)

22 Day NE, Boice JD Jr, eds. Second cancer in relation to radiation treatment for cervical cancer. Lyons: International Agency for Research on Cancer, 1983. (IARC scientific publications, No 52.)

23 Beral V, Fraser P, Booth M, Carpenter L. Epidemiological studies of workers in the nuclear industry. In: Russell Jones R, Southwood R, eds. Radiation and health. Chichester: Wiley, 1987:97-106.

24 Beral V, Carpenter L, Booth M, Inskip H, Brown A. The "healthy worker effect" and other determinants of mortality in workers in the nuclear industry. In: Health effects of low dose ionising radiation-recent advances and their implications. London: British Nuclear Energy Society, 1988:95-100.

25 Shimizu Y, Kato H, Schull WJ, Preston DL, Fujita S, Pierce DA. Life span study report 11. Part 1. Comparison of risk coefficients for site-specific cancer mortality based on the DS86 and T65DR shielded Kerma and Organ doses. Radiation Effects Research Foundation Technical Report Series 1987; doses. Radicior

26 Alderson MR. Prostate cancer: epidemiology. Recent Results Cancer Res 1981;78:1-19.

27 Piscator $M$. Role of cadmium in carcinogenesis with special reference to cancer of the prostate. Environ Health Perspect 1981;40:107-20.

28 Schroeder HA, Nason AP, Tipton IH, Balassa JJ. Essential trace metals in man: zinc. Relation to environmental cadmium. $f$ Chronic Dis 1967;20: 179-210.

29 Fraser P, Beral V, Booth M, Inskip H, Carpenter L. Epidemiological studies of employees of the United Kingdom Atomic Energy Authority. In: Health effects of low dose ionising radiation-recent advances and their implications. London: British Nuclear Energy Society, 1988:67-70.

30 Hodge HC, Stannard JN, Hursh JB. Uranium, plutonium and the transplutonic elements. New York: Springer Verlag, 1973.

31 Waxweiler RJ, Roscoe RJ, Archer VE, Thun MJ, Wagoner JK, Lundin FE Jr. Mortality follow-up through 1977 of the white underground uranium miners cohort examined by the United States Public Health Service. In: Gomez M, ed. Radiation hazards in mining. Kingsport: Kingsport Press, 1981:823-30. 32 International Commission for Radiological Protection. Limits of intakes of radionuclides by workers. Part 1. Ann ICRP 1979; No 30:1-116.

33 Pochin E. Report of an investigation into radiological health and safery at the Ministry of Defence (Procurement Executive) Atomic Weapons Research Establishment, Aldermaston. Harwell, Oxfordshire: Atomic Weapons Research Establishment, 1978.

34 Preston DL, Pierce DA. The effect of changes in dosimetry on cancer mortality risk estimates in the atomic bomb survivors. Radiation Effects Research Foundation Technical Report Series 1987; No 9:1-50.

(Accepted 5 August 1988)

\title{
Surveillance of antibody to measles, mumps, and rubella by age
}

\author{
Peter Morgan-Capner, Jean Wright, Christine L Miller, Elizabeth Miller
}

\begin{abstract}
Before the introduction of measles, mumps, and rubella vaccine a survey was carried out to measure antibody prevalence to the three viruses by age. A total of 8716 samples of serum collected by five public health laboratories in different parts of England during 1986-7 were tested. Despite the current measles vaccination programme $60 \%$ of children aged 1-2 years did not have measles antibody and over $80 \%$ did not have antibodies to mumps and rubella. In the 3-4 year age group $17 \%$ of the children were susceptible to measles, $55 \%$ to mumps, and $73 \%$ to rubella. The results suggest that vaccinating children early in the second year of life will be necessary to eliminate the three diseases.
\end{abstract}

The survey provides baseline data for continuing surveillance of the immediate and long term effects of the new vaccination strategy.

\section{Introduction}

Development of effective strategies of vaccination and assessment of their impact require knowledge of the prevalence of antibody by age for the diseases concerned. Preceding the introduction of measles, mumps, and rubella vaccine, a study of antibody prevalence to measles, mumps, and rubella viruses across the age range 1-65 years and over has been carried out. This has provided information on the most suitable age for vaccination and baseline data on antibody prevalence as part of continuous surveillance to monitor both immediate and long term effects of introducing the vaccine.

\section{Subjects and methods}

In five public health laboratories (Ashford, Bristol, Leeds, Manchester, and Preston) serum remaining from samples submitted for routine diagnostic examination was saved from patients aged 1-65 years and over. Samples from immunocompromised patients and samples sent for testing for antibody to hepatitis B and the human immunodeficiency virus were excluded.

The serum samples were tested for rubella antibody by radial haemolysis ${ }^{1}$ in each laboratory. Samples giving zone sizes greater than that of a control serum containing 15 IU rubella antibody were recorded as positive and those with no zone as negative. Samples giving small zones compared with the control serum or zones on both test and control gels were retested at Preston Public Health Laboratory by latex agglutination (Orion Diagnostica, Espoo, Finland) and recorded as positive or negative accordingly. Samples were tested for measles and mumps antibodies at Preston Public Health Laboratory. Mumps antibody was detected by radial haemolysis. ${ }^{2}$ A serum (arbitrarily assigned as having 50 units of antibody) from a person who had had mumps in the remote past was diluted in negative serum. At a dilution of one in 10 (5 antibody units) antibody was reproducibly detected by radial haemolysis during preliminary evaluation, and this dilution was tested on every gel. Test samples giving zones of haemolysis greater than that of the diluted standard were considered to 're positive and those giving no zone negative. Samples giving zones on test and control gels were retested after absorption with day old chick red cells and non-infected allantoic fluid. Samples giving zones less than that of the diluted standard were retested with a commercial antiglobulin enzyme linked immunosorbent assay (ELISA) (Behringwerke AG, Marburg, West Germany) and classified according to result. Measles antibody was detected by haemagglutination inhibition. ${ }^{3}$ Serum samples were compared with a serum standardised against the first British standard human antimeasles serum and samples with a concentration equal to or greater than $0.3 \mathrm{IU}$ (usually a titre of 8 by haemagglutination inhibition) were considered to be positive, and those with a concentration below $0 \cdot 15 \mathrm{IU}$ negative. Samples with a concentration of $0 \cdot 15$ IU were retested with a commercial antiglobulin ELISA and assigned as positive or negative according to the result 
obtained. Final results were analysed at the Communicable Disease Surveillance Centre.

\section{Results}

Results were obtained for 8716 serum samples taken between November 1986 and December 1987. An average of 250 samples were tested for each year of age from 1-14, two years of age from 15-34, five years from $35-44$, and 10 years thereafter. There were no consistent differences among laboratories in the proportions of subjects who were susceptible to measles, mumps, and rubella at different ages. The results from all five laboratories have therefore been summed (table I).

TABLE I-Number (percentage) of serum samples negative for antibody to measles, mumps, and rubella by age

\begin{tabular}{lcrll}
\hline Age (years) & No of samples & Measles & Mumps & Rubella \\
\hline $1-<2$ & 398 & $237(60)$ & $354(89)$ & $347(87)$ \\
$2-<3$ & 290 & $86(30)$ & $248(86)$ & $239(82)$ \\
$3-<4$ & 324 & $60(19)$ & $200(62)$ & $260(80)$ \\
$4-<5$ & 365 & $56(15)$ & $136(37)$ & $244(67)$ \\
$5-9$ & 1474 & $138(9)$ & $336(24)$ & $647(44)$ \\
$10-12$ & 876 & $45(5)$ & $118(13)$ & $184(12)$ \\
$13-16$ & 903 & $42(5)$ & $105(12)$ & $111(12)$ \\
$17-30$ & 2366 & $117(5)$ & $208(9)$ & $174(7)$ \\
$31-\geqslant 65$ & 1720 & $66(4)$ & $172(10)$ & $124(7)$ \\
\hline
\end{tabular}

Sixty per cent of children in the second year of life did not have measles antibody, the proportion decreasing to $30 \%$ during the third year. In contrast, over $80 \%$ of children of the same age did not have antibodies to mumps and rubella. Susceptibility to mumps declined sharply in the $3-<5$ age group; that to rubella declined later. After the age of 12 there was no significant downward trend in the proportions of subjects who did not have measles or mumps antibody.

As shown in table II, the proportions of subjects who did not have rubella antibody were significantly lower in females than in males in age groups between 10 and $30(p<0.01)$, reflecting the effect of selective rubella vaccination of girls and women. Susceptibility in women too old to have been offered rubella vaccine at

TABLE II - Serum samples negative for antibody to rubella by age and $\operatorname{sex}$

\begin{tabular}{|c|c|c|c|c|}
\hline \multirow[b]{2}{*}{ Age (years) } & \multicolumn{2}{|c|}{ Male } & \multicolumn{2}{|c|}{ Female } \\
\hline & No of samples & No(\%) & No of samples & No $(\%)$ \\
\hline 1. 2 & 343 & $295(86)$ & 345 & $291(84)$ \\
\hline $3-$ & 350 & $265(76)$ & 339 & 239 (71) \\
\hline $5-9$ & 826 & 371 (45) & 648 & $276(43)$ \\
\hline $10-12$ & 468 & $121(26)$ & 408 & $63(15)$ \\
\hline $13-16$ & 454 & $96(21)$ & 449 & $15(3)$ \\
\hline 17- 30 & 1183 & $130(11)$ & 1183 & $44(4)$ \\
\hline $31-\geqslant 65$ & 859 & $66(8)$ & 861 & $58(7)$ \\
\hline
\end{tabular}

school (31 and over) was higher than in younger women and not significantly different from that in men of the same age. There was no significant difference between the sexes in the proportions without antibody to either measles or mumps at any age.

\section{Discussion}

This is the largest survey of the prevalence of antibodies to measles, mumps, and rubella viruses across the whole age range to be reported in the United Kingdom. The subjects tested were not randomly sampled from the population as this is not feasible for ethical, practical, and financial reasons. Each laboratory in the study, however, serves a large and fairly constant catchment area; by using the same laboratories in repeat surveys future changes in the prevalence of antibody by age in these populations should become apparent. During 1988 other laboratories, including one in London, have been included in the surveillance. The assays used for detecting antibodies to measles, mumps, and rubella are well established and appropriate for testing large numbers of serum samples. The use of standard control serum will ensure comparability with results in future years.

The lower proportion of children aged $1-<3$ susceptible to measles compared with mumps and rubella reflects the current uptake of measles vaccine of around $70 \%$ by the end of the second year of life. ${ }^{4}$ The decline in susceptibility to measles in children aged 3-5 is more probably due to infection than to vaccination at this age, as a yearly average of 40000 cases have been notified in children under 5 in the past few years. ${ }^{5}$ The data show that mumps is also predominantly a preschool infection as by the age of 5 only $33 \%$ of children are still susceptible. Clearly, to control the circulation of measles and mumps vaccination early in the second year of life is important. Though the data show that rubella is acquired later than measles and mumps, maximum effect will still be achieved by early vaccination.

During the first few years of the programme measles, mumps, and rubella vaccine will also be offered to all children aged 4-5 to reduce the number of susceptible children entering school and thereby limit the spread of infection in the primary school population. This should be particularly valuable for rubella as the data show that two thirds of children are still susceptible when they enter school. For practical reasons the main target of the "catch up" programme will be children attending for their preschool diphtheria and tetanus booster, but in addition no opportunity should be missed to vaccinate children aged 2-4. In future years vaccination of preschool children should apply only to those whose measles, mumps, and rubella vaccination has been missed. It should not be regarded as an alternative opportunity, as delaying immunisation to this age will inevitably allow continuing circulation of the viruses in the preschool population. This has been observed in the United States, where laws on school entry ensure a high uptake at that age, but where outbreaks of measles continue in preschool children. ${ }^{6}$

A two stage vaccination policy at 1-2 years of age and again at 12, adopted in Sweden, ${ }^{7}$ would not be justified here at present because of the fairly small proportion of children currently susceptible in the older age group. If future surveillance, however, shows an increase in the proportions of older children who do not have antibodies a two stage vaccination programme might become appropriate.

Susceptibility to measles and mumps did not decline significantly after 12 . With rubella, however, there is some evidence that antibody titres decline with age, ${ }^{8}$ and some of the older subjects in our study who were categorised as having no rubella antibody might have antibody detected by alternative techniques. Serum samples that were negative on the initial screening have not so far been retested. Mass vaccination will inevitably have a profound effect on the epidemiology of measles, mumps, and rubella. The immediate effect should be an increase in prevalence of antibodies in the vaccinated cohorts. In the long term, however, indirect effects may occur in the older age groups, in which reduced exposure to disease could result in increased susceptibility, thereby allowing the continued circulation of the viruses. The serological surveillance described, together with the monitoring of the incidence of disease and uptake of the vaccine will allow such susceptible cohorts to be identified and the necessary action taken to eliminate measles, mumps, and rubella.

We thank Mr P Vaghela for his technical assistance, Dr Jennings for providing the mumps antigen, Mr B Fisher 
for supplying the chicks, and the staff in the five public health laboratories for their cooperation.

1 Kurtz JB, Mortimer PP, Morgan-Capner P, Shafi MS, White GBB. Rubella antibody measured by radial haemolysis. Characterisation and performance of a simple screening method for use in diagnostic laboratories. fournal of Hygiene 1980;84:213-2.

2 Mortimer PP. Mumps prophylaxis in the light of a new test for antibody BrMed $\mathcal{F}$ 1978;ii:1523-4.

3 Gershon AA, Krugman S. Measles virus: In: Lennette EH, Schmidt NJ, eds. Diagnostic procedures for viral, rickettsial and chlamydial infections. 5th ed. Washington: American Public Health Association, 1979:665-93.
4 Department of Health and Social Security. Statistics and research. London: DHSS, 1987. (SR2B.)

5 Office of Population Censuses and Surveys. Communicable disease statistics. London: OPCS, 1987. (MB2.)

Centers for Disease Control. Measles in United States, first 26 weeks 1987. MMWR 1988;37:53-7.

7 Rabo E, Taranger J. Scandinavian model for eliminating measles, mumps, and rubella. Br Med $\mathcal{F}$ 1988;289:1402-4.

8 Nokes DJ, Anderson RM, Anderson MJ. Rubella epidemiology in south east England. Foumal of Hygiene 1986;96:291-304.

(Accepted 6 September 1988 )

\section{Sclerosis of lytic bone metastases after disodium aminohydroxypropylidene bisphosphonate (APD) in patients with breast carcinoma}

\author{
A R Morton, J A Cantrill, G V Pillai, \\ A McMahon, D C Anderson, A Howell
}

University Departments of Medicine and Pharmacy, Hope Hospital, Salford M6 8HD

A R Morton, MRCP, research fellow

J A Cantrill, MPS, staff pharmacist

G V Pillai, MPS, pharmacist

DC Anderson, FRCP,

professor of endocrinology

\section{Department of Medical} Oncology, Christie

Hospital and Holt Radium

Institute, Manchester

A McMahon, BSC, research

nurse

A Howell, FRCP, senior

lecturer in medical oncology

Correspondence to:

Dr Howell.
Bisphosphonates, which are potent inhibitors of osteoclast function, reduce morbidity from bone metastases when used with systemic chemotherapy. ${ }^{1}$ The contribution of each treatment in any patient is not known. We assessed the effect of disodium aminohydroxypropylidene bisphosphonate (APD) used either alone or in patients receiving endocrine treatment whose disease was progressing.

\section{Patients, methods, and results}

We studied 16 patients with breast carcinoma who had progressing metastases in bone for six months or until their disease progressed again despite treatment. APD (Ciba-Geigy) was administered intravenously (30 $\mathrm{mg}$ in $500 \mathrm{ml}$ of $0.9 \%$ saline over two hours) weekly for four weeks and thereafter fortnightly. At each visit we measured serum calcium, albumin, and phosphate concentrations; alkaline phosphatase activity; and ratios of fasting urinary calcium to creatinine and hydroxyproline to creatinine concentrations. Serum concentrations of osteocalcin and tumour markers (carcinoembryonic antigen and carbohydrate antigen $15: 3^{2}$ ) were measured monthly. Pain was scored on a linear analogue scale and the Karnofsky performance state assessed at each visit. A baseline isotope bone scan and plain radiographs of the chest, thoracolumbar spine, and pelvis were obtained. Radiography was repeated every six weeks. Evidence of sclerosis in a previously lytic lesion in the absence of new lesions was taken as a response to treatment. Statistical analysis was by Friedman's non-parametric two way analysis of variance.

Patients tolerated the infusions of APD well. Eight patients were withdrawn within six months with evidence of progressing disease (three in bone, five at other sites).

Effect on symptoms-Patients' perception of their pain, expressed as a percentage on the linear analogue scale, decreased significantly $(p<0.01)$ from a median of $69 \%$ (range $42-90 \%$ ) to $32 \%(5-75 \%)$ but was unrelated to radiological response. The Karnofsky performance state improved from a median of 70 (range 50-80) to $80(60-90)(\mathrm{p}<0.025)$.

Effects on biochemical variables-No significant change in serum calcium or phosphate concentrations occurred. The molar ratio of urinary calcium to creatinine concentrations fell significantly from a median of 0.63 (range $0 \cdot 10-1 \cdot 38)$ to $0.12(0.02-0.67)$ $(p<0.001)$ after the first infusion of APD. Patients who showed radiological improvement tended to have particularly low urinary ratios. The ratio rose dramatically in three patients whose disease progressed in bone. No significant change in alkaline phosphatase activity, osteocalcin concentration, or ratio of urinary hydroxyproline to creatinine concentrations was seen.

Antitumour effect-At six months radiological evidence of sclerosis of lytic metastases (figure) was seen in four patients and no change in the other four.
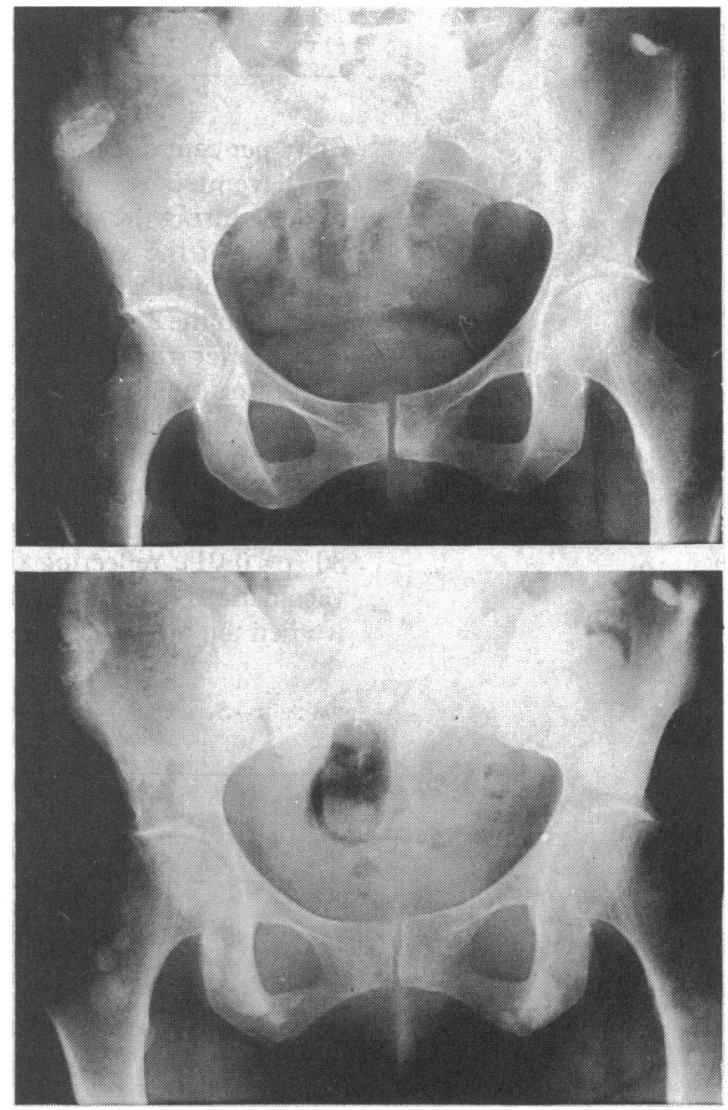

Lytic bone metastases before (top) and after (bottom) treatment with $A P D$

Concentrations of both carcinoembryonic antigen and carbohydrate antigen 15:3 fell in three patients (two who had a partial response and one whose disease remained stable), remained unchanged in eight patients, and rose in five.

\section{Comment}

APD produced sclerosis of lytic metastases in four patients, and in four others the disease remained stable by radiological criteria over six months. Patients who responded to APD seemed to show greatest suppression of bone resorption as reflected in their low ratios of urinary calcium to creatinine concentrations. Tumour marker concentrations fell in three of the 